\title{
AGLOMERAÇÕES, RECESSÃO E CRESCIMENTO DO EMPREGO: UMA ANÁLISE PARA OS MUNICÍPIOS BRASILEIROS
}

\author{
Cristian Rafael Pelizza* \\ Sabino da Silva Pôrto Junior**
}

\begin{abstract}
Resumo
O trabalho busca analisar se o impacto das crises econômicas sobre o crescimento do emprego, nos municípios brasileiros, é afetado pelo nível de aglomeração econômica. Para tanto, os municípios foram agrupados em diferentes níveis, de acordo com sua densidade populacional. Para a estimação, utilizou-se uma estratégia difference-in-differences com dados em painel para o período 2003-2011, tendo como referência a influência da crise ocorrida em 2008. Além disso, utilizaram-se controles associados a composição do mercado de trabalho, da indústria e da localização municipal. De maneira geral, os resultados indicam maior sensibilidade à crise nos municípios com baixa aglomeração ao utilizar como variável dependente o crescimento do emprego total. Para o crescimento do emprego na indústria de transformação os municípios com alta aglomeração apresentaram menor crescimento pós-crise.
\end{abstract}

Palavras chave: aglomerações; recessão; crescimento do emprego.

\section{AGGLOMERATIONS, RECESSION AND EMPLOYMENT GROWTH: AN ANALYSIS OF BRAZILIAN MUNICIPALITIES}

\begin{abstract}
The work seeks to analyze whether the impact of economic crises on employment growth in Brazilian municipalities is affected by the level of economic agglomeration. To this end, the municipalities were grouped at different levels, according to their population density. For the estimation, a difference-in-differences strategy with panel data for the period 2003-2011 was used, having as reference the influence of the crisis that occurred in 2008. In addition, controls associated with the composition of the labor market, industry and municipal location were used. In general, the results indicate greater sensitivity to the crisis in municipalities with low agglomeration when using the growth of total employment as a dependent variable. For employment growth in the manufacturing industry, municipalities with high agglomeration showed lower post-crisis growth.
\end{abstract}

Key words: agglomerations; recession; employment growth

JEL Classification: R11, R23.

\footnotetext{
* Doutor em Economia pela Universidade Federal do Rio Grande do Sul (UFRGS) e Professor na Universidade Comunitária da Região de Chapecó (UNOCHAPECÓ). E-mail: cpelizza@ unochapeco.edu.br

** Doutor em Economia pela Universidade Federal do Rio Grande do Sul (UFRGS) e Professor do Programa de Pós-Graduação em Economia da Universidade Federal do Rio Grande do Sul (UFRGS). E-mail: sabino@ppge.ufrgs.br
} 


\section{INTRODUÇÃO}

Como exposto por Fujita e Thisse (2013), as economias tendem a se concentrar espacialmente e a principal razão são as chamadas economias de aglomeração ${ }^{1}$ decorrentes da consolidação do mercado potencial local que acaba mais atraindo do que expulsando empresas e pessoas para uma dada localidade. A literatura sobre a existência, extensão e sobre o impacto das economias de aglomerações ${ }^{2}$ sobre a produtividade e o crescimento do emprego local é ampla, tanto do ponto de vista teórico, como empírico, ver, por exemplo, Duranton e Puga (2004) e Ottaviano e Thisse (2004).

Segundo dados do Instituto Brasileiro de Geografia e Estatística (IBGE) para o ano de 2014, os dez municípios em ordem decrescente com maior Produto Interno Bruto (PIB) do Brasil - São Paulo, Rio de Janeiro, Brasília, Belo Horizonte, Curitiba, Manaus, Porto Alegre, Osasco, Campos dos Goytacazes e Campinas - respondiam por aproximadamente 27,64\% de todo o produto nacional. No entanto, os mesmos municípios respondem por apenas $0.30 \%$ do território do país. Esse padrão de distribuição espacial da atividade econômica corrobora a tese de tendência à concentração da atividade econômica, em poucos locais no espaço.

O presente trabalho busca investigar se existem assimetrias do impacto da recessão entre diferentes níveis de aglomeração econômica espacial no Brasil. Para tanto, analisam-se o dinamismo econômico dos municípios brasileiros no período de 2003 a 2011, que engloba a grande crise econômica ocorrida em 2008. Assim, analisa-se o comportamento do emprego total e da indústria de transformação no período 2003-2011 para todos os municípios brasileiros. A hipótese básica é a de que o efeito da crise de 2008 sobre os municípios brasileiros não foi espacialmente homogêneo, pois o impacto da crise econômica de 2008 depende da existência ou não de aglomerações locais.

Portanto, o objetivo principal desse trabalho é avaliar se as economias de aglomeração amenizaram ou ampliam o impacto da recessão no Brasil, através do método de difference-indifferences. Para tanto, os municípios foram agrupados em diferentes níveis de aglomeração a partir de suas densidades populacionais em 2003.

\footnotetext{
${ }^{1}$ Combes e Gobillon (2015), sugerem que as economias de aglomeração, de maneira geral, referem-se a qualquer efeito que aumenta a renda das firmas e trabalhadores quando o tamanho da economia local aumenta.

${ }^{2}$ Entre as diversas fontes das economias de aglomeração é possível citar as externalidades maarshalianas, resumidas por Duranton e Puga (2004) em compartilhamento (sharing), correspondência (matching) e aprendizado (learning); e, a abordagem que ressalta como fonte principal as interações entre retornos crescentes de escala e redução dos custos de transporte realizada por Krugman (1991).
} 
O trabalho está dividido em cinco seções, além da introdução. A segunda seção apresenta uma revisão da literatura dos efeitos das economias de aglomeração, em particular sobre o emprego regional. A seção 3 contém o modelo empírico a ser estimado. A seção 4 discute os critérios adotados para construção dos grupos de municípios de alta e baixa aglomeração, e apresenta algumas estatísticas descritivas das variáveis usadas na pesquisa. A quinta seção explicita os resultados obtidos. E, na sexta seção faz as considerações finais

\section{Revisão da literatura}

Duranton e Puga (2004) classificam os efeitos das aglomerações em três tipos: compartilhamento (sharing), correspondência (matching) e aprendizado (learning). A aglomeração e a consequente formação de mercados maiores levam a um ganho na produtividade do trabalhador devido ao uso compartilhado de bens indivisíveis e de instalações, e ao acesso a um número maior de bens intermediários, além do compartilhamento de ganhos com a especialização individual e divisão de riscos. Aglomerações - cidades maiores- também propiciam que ocorram um melhor casamento (match) entre firmas e trabalhadores, e isso tende a aumentar a qualidade esperada de cada correspondência (match). Além disso, nesse ambiente a probabilidade de acontecer a correspondência aumenta. Seguindo ideias de Marshall (1890) e Jacobs (1969), argumentam também que o ambiente urbano propicia uma maior facilidade na geração, difusão e acumulação de conhecimento entre os agentes e, portanto, um ambiente mais favorável ao aprendizado.

Os modelos da Nova Geografia Econômica de Fujita (1988), Krugman (1991) e Venables (1996), dentre outros, ressaltam o papel das interações entre retornos de escala e custos de transporte nos padrões de concentração espacial das atividades econômicas.

Ciccone e Hall (1996) usam a densidade populacional como indicador da magnitude da aglomeração local. Uma analise empírica é estimar o efeito da aglomeração local sobre salários e sobre a produtividade local. Glaeser e Maré (2001) buscam isolar efeitos de heterogeneidade nos indivíduos e heterogeneidade local sobre a dinâmica local. E, Baun-Snow e Pavan (2012) avançam na análise das heterogeneidades individuais.

Combes et al (2008), estudam o problema de auto seleção na escolha do local de moradia do trabalhador. Assim, indivíduos com maiores habilidades escolhem viver em locais com maior aglomeração e isso acaba influenciando os salários locais. Outros trabalhos também analisam os efeitos dinâmicos das economias de aglomeração, como em De la Roca e Puga 
(2017). Redding e Venables (2004) e Hanson (2005) analisam o efeito do potencial de mercado sobre a concentração e dinâmica das atividades econômicas em uma dada região.

Glaeser e Mare (1992) analisam os efeitos sobre o crescimento do emprego em cidades americanas de três tipos de externalidades relacionadas à externalidades de tecnológicas sobre a economia local. Utilizando dados de 170 cidades entre 1956 e 1987, e uma estimação com cross-section, encontraram efeito positivo da diversidade e competição sobre o crescimento do emprego.

Henderson et al (1995) analisam o crescimento do emprego em oito setores da indústria para 224 áreas metropolitanas americanas, entre 1970 e 1987. Os resultados indicam efeitos positivos sobre a geração de empregos nas áreas analisadas das externalidades (JACOBS, 1969). Porém, para indústrias de bens de capital maduras, apontam que prevalece o efeito positivo da concentração setorial, ou externalidades Marshall-Arrow- Romer (MAR); enquanto, a diversidade de setores não impacta o emprego regional ou local. Contudo, para novas indústrias, em especial do setor tecnológico, são observados efeitos positivos de ambas as externalidades.

Combes (2000) analisa o crescimento do emprego industrial em 341 áreas locais francesas para o período 1984-1993. Para tanto, utilizou-se de 54 setores industriais e 42 setores de serviços, e estudou o impacto da especialização e da diversidade, da competição, do tamanho médio das plantas e da densidade total do emprego. A principal conclusão sustenta que os efeitos diferem entre os setores industriais e de serviços. Para os setores industriais a densidade, a competição e o tamanho das plantas reduzem o emprego, enquanto, para alguns setores também a especialização e a diversidade apresentaram impacto positivo sobre o emprego local.

Viladecans-Marsal (2004) distingue dois tipos de economia de aglomeração: economias de urbanização, associadas a população e emprego municipal, e aglomeração de diversidade da estrutura produtiva local. Então, estudam o impacto destes tipos de aglomeração sobre o emprego em diversos setores industriais nos municípios espanhóis. Os resultados obtidos indicam que tanto as economias de urbanização quanto de localização afetam positivamente o padrão de emprego local, sendo a primeira mais preeminente em setores tecnologicamente avançados e a segunda em setores mais tradicionais.

Blien e Suedekum (2005) retomam o estudo dos efeitos das externalidades MAR e de Jacobs (1969) sobre o crescimento do emprego da indústria e do setor serviços em 438 distritos alemães entre 1993 e 2001. Os resultados indicam que tanto as externalidades MAR quanto de Jacobs (1969) afetam positivamente a indústria. O setor serviços só é beneficiado por externalidades de tipo MAR. 
Na mesma linha, Blien et al (2006) analisaram efeitos dinâmicos das aglomerações sobre o crescimento do emprego nas regiões da Alemanha entre 1980 e 2001. Para tanto, utilizam um painel dinâmico para dados de emprego da indústria e do setor serviços de 326 distritos alemães. A externalidade decorrente da diversidade e da especialização impacta positivamente tanto o setor industrial como o setor serviços. Já a externalidade decorrente da estrutura local de capital humano apresentou influência positiva apenas sobre o setor industrial.

Badia e Figueiredo (2007) utilizam um painel dinâmico e externalidades de tipo MAR e de Jacobs (1969), para estudar o impacto das economias de aglomeração sobre o crescimento do emprego em diversos setores industriais no Brasil. Encontram, tanto a diversidade industrial quanto a escala passada da indústria, e o grau de competição com o qual as firmas desta indústria se deparam e impactam positivamente o crescimento do emprego industrial nas cidades brasileiras. Matlaba et al (2012) comparam estimativas dos efeitos de externalidades sobre o emprego para 26 estados brasileiros. Para a análise em cross section, os autores reportam efeitos positivos das externalidades de Jacobs (1969) e de Porter (1990) e, para dados em painel encontram efeitos benéficos das externalidades MAR e de Porter (1990).

Embora a literatura sobre os impactos das recessões sobre o emprego em escala agregada para países seja ampla ${ }^{3}$, os estudos dos efeitos locais das recessões da sua relação com as economias de aglomeração são menos explorados. Trabalhos nessa linha são raros. Brunello e Langella (2016), por exemplo, analisam o impacto da crise econômica global de 2008 sobre o empreendedorismo em regiões italianas. Guiso e Schivardi (2007), na mesma direção, mas um pouco diferente, estudam os efeitos de spillovers tecnológicos sobre distritos industriais.

\section{Estratégia empírica e base de dados}

Para observar o efeito da recessão de 2008, em diferentes níveis de aglomeração, sobre os municípios brasileiros utilizou-se a estratégia difference-in-differences para cinco amostras diferentes de municípios, resumidas na Tabela 1 abaixo. Para o analise do comportamento do emprego total foram empregadas as primeiras três amostras, enquanto que para analise do emprego na indústria as duas amostras restantes. Na definição das amostras buscou-se eliminar municípios com nível de emprego excessivamente baixo. Essa estratégia visa eliminar possíveis efeitos de escala sobre as taxas de crescimento observadas.

\footnotetext{
${ }^{3}$ Ver Shimer (2010).
} 
A distinção entre níveis de aglomeração dos municípios foi feita através das densidades ${ }^{4}$ populacionais locais observadas no ano de 2003. Cada amostra foi dividida em quartis por densidade populacional. Os municípios do quartil superior são considerados de alta aglomeração e os do quartil inferior de baixa aglomeração.

O objetivo é testar, via modelos difference-in-differences ${ }^{5}$, se as taxas de crescimento do emprego nos municípios de alta aglomeração foram mais ou menos impactados após a crise econômica de 2008, quando comparadas aos municípios baixa aglomeração. Para as aplicações empíricas presentes nas cinco amostras foram utilizados 5.559 municípios brasileiros no período de 2003 a 2011.

O modelo básico estimado, com uma especificação difference-in-differences, para os $i$ municípios presentes em cada amostra, pode ser expresso por:

$$
g E m p_{i t}=\beta_{0}+\beta_{j} J+\beta_{q} Q+\beta_{d} J \cdot Q+\beta_{x} g X_{i t}+\beta_{s} g S_{i t}+\beta_{m} g M_{i t}+u_{i t}
$$

O modelo busca observar o comportamento do crescimento do emprego gEmp $p_{i t}$, como função do período (pré e pós-recessão) e do nível de aglomeração (alta ou baixa), além de variáveis $^{6}$ de controle adicionais.

O crescimento do emprego $g E m p_{i t}$ pode ser expresso por:

$$
g E m p_{i t}=\log E m p_{i t}-\log E m p_{i t-1}
$$

Onde $E m p_{i t}$ representa o nível de emprego no município $i$ no período $t$.

Observe-se que é possível utilizar efeitos fixos temporais $\beta_{j} J$, com $J=1$ para período pós-recessão (2008-2011) e $J=0$ para períodos anteriores a recessão (2003-2007). Já, os efeitos espaciais são detectados por $\beta_{q} Q$, onde $Q=1$ indica os municípios do grupo de alta aglomeração e $Q=0$ indica os municípios que fazem parte do grupo de baixa aglomeração em 2003. Enquanto, as variáveis $g X_{i t}, g S_{i t}$ e $g M_{i t}$ são variáveis de controles adicionais para características locais, respectivamente, mercado de trabalho, indústria no município e amenidades locais.

\footnotetext{
${ }^{4}$ A utilização da densidade populacional como indicador do nível de aglomeração remonta ao trabalho de Ciccone e Hall (1996) e é empregada em diversos trabalhos como em Combes e Gobillon (2015).

${ }^{5}$ A utilização do método difference-in-diferences em economia regional e urbana pode ser vista, por exemplo, em Redding e Sturm (2008), Greenstone et al (2010), Baum-Snow e Lutz (2011) e Brunello e Langrella (2016).

${ }^{6}$ As variáveis apresentadas são especificadas em taxas de crescimento, exceto aquelas fixas no tempo.
} 
Assim, a estimação de $\hat{\beta}_{d}$ captura o efeito dif-in-dif entre a variação do emprego antes e depois da recessão e entre os grupos com alta e baixa aglomeração:

$$
\begin{aligned}
& \hat{\beta}_{d}=[E(g E m p \mid g X, g S, g M, Q=1, J=1)-E(g E m p \mid g X, g S, g M, Q=1, J=0)] \\
& -[E(g E m p \mid g X, g S, g M, Q=0, J=1)-E(g E m p \mid g X, g S, g M, Q=0, J=0)]
\end{aligned}
$$

Por sua vez, o parâmetro $\beta_{q}$ irá capturar diferenças observadas no crescimento do emprego entre os dois grupos, de alta e de baixa aglomeração, independentemente da recessão, enquanto o parâmetro $\beta_{j}$ buscar capturar efeitos da recessão que são comuns aos dois grupos de municípios.

As variáveis $g X_{i t}, g S_{i t}$ e $g M_{i t}$ presentes na expressão (1) têm como objetivo acrescentar controles que capturam os efeitos da composição do mercado de trabalho, composição da indústria e setores, e das amenidades dos municípios sobre o crescimento do emprego no período (GLAESER; MARE, 1992). Para as estimações do efeito das aglomerações sobre o crescimento do emprego na indústria de transformação, as variáveis de controle referem-se apenas a própria indústria de transformação.

As variáveis de composição do mercado de trabalho $g X_{i t}$, para os $i$ municípios da amostra utilizadas foram: crescimento dos salários $\left(g W_{i t}\right)$, crescimento do percentual de trabalhadores de alta qualificação $\left(g H S_{i t}\right)$, crescimento do percentual de trabalhadores com baixa qualificação $\left(g H L_{i t}\right)$, crescimento da participação percentual feminina e masculina na força de trabalho $\left(g\right.$ Women $\left._{i t}\right)$. O crescimento dos salários por sua vez, foi definido por $g W_{i t}=$ $\log W_{i t}-\log W_{i t-1}$. Onde $W_{i t}$ são os salários médios no período $t$ e no município $i$ (GLAESER; MARE, 1992).

Observe-se que o percentual de trabalhadores com alta qualificação $H S_{i t}$ é obtido a partir da divisão do total de trabalhadores com pelo menos o ensino superior completo $\left(L H_{i t}\right)$ dividido pelo total de trabalhadores no município $\left(L_{i t}\right)$, tem-se então que: $H S_{i t}=L H_{i t} / L_{i t} \mathrm{e}$ $g H S_{i t}=H S_{i t}-H S_{i t-1}$. Para o percentual de trabalhadores com baixa qualificação $\left(H L_{i t}\right)$ dividiu-se o total de trabalhadores com no máximo o ensino fundamental completo $\left(L L_{i t}\right)$ pelo total de trabalhadores municipal $\left(L_{i t}\right): H L_{i t}=L L_{i t} / L_{i t}$ e $g H L_{i t}=H L_{i t}-H L_{i t-1}{ }^{7}$.

A participação percentual do trabalho feminino é definida por Women $_{i t}=$ LWomen $_{i t} / L_{i t}$. As taxas de variação são expressas por $g W o m e n_{i t}=$ Women $_{i t}-$

\footnotetext{
${ }^{7}$ Como essas variáveis são expressas em taxa percentual, optou-se por não as utilizar em uma especificação logarítmica para estimar o crescimento de $\mathrm{H}$.
} 
Women $_{i t-1^{8}}$. Como aumentos na participação feminina resultam em diminuição da participação masculina, a variável pode ser usada também para observar o impacto da participação masculina na força de trabalho.

Como controles para atividades setoriais utilizou-se a variação na proporção da agricultura (A), dada por $\left(g A_{i t}\right)$ e da indústria (I), dada por $\left(g I_{i t}\right)$, para $i$ municípios e $t$ períodos. Estimadas da seguinte forma:

$$
g k_{i t}=\frac{L k_{i t}}{L_{i t}}-\frac{L k_{i t-1}}{L_{i t-1}}
$$

Onde $k=A, I$, ou seja, cada um dos setores analisados. Os empregos setoriais são dados por $L k_{i t}$ e $L k_{i t-1}$ e os empregos totais nos períodos $t$ e $t-1$ no município $i$ são $L_{i t}$ e $L_{i t-1}$.

Usou-se também o grau de especialização local como variável de controle. Para mensurar o grau de especialização do município estimou-se o índice de Hirschman-Herfindahl $\left(H H I_{i t}\right)$, expresso por:

$$
H H I_{i t}=\left(\sum_{s} \frac{L_{s i t}}{L_{i t}}\right)^{2}
$$

Onde $L_{s i t}$ é o emprego no setor industrial $s$, no município $i$ e no período $t$, e $L_{i t}$ é o emprego somando todos os $s$ setores no município i. Para os modelos em que a variável dependente foi o crescimento emprego total do município, foram utilizados 63 setores envolvendo agricultura, indústria e comércio/serviços. Para modelos em que a variável dependente foi o crescimento do emprego na indústria de transformação. foram utilizados 22 setores. A divisão setorial utilizada foi o CNAE 95 (Classificação Nacional das Atividades Econômicas), definido pelo Instituto Brasileiro de Geografia e Estatística (IBGE). A taxa de crescimento do índice é dada por $g H H I_{i t}=\log H H I_{i t}-\log H H I_{i t-1}$.

Para capturar os efeitos de amenidades locais utilizou-se também as seguintes variáveis de controle para cada município: latitude $\left(L a t_{i}\right)$ e longitude $\left(\operatorname{Lon}_{i}\right)$. Essas variáveis visam controlar o efeito de características como pluviosidade e temperatura no comportamento do crescimento do emprego local.

\footnotetext{
${ }^{8}$ Não se utilizou especificação logarítmica, pois as variáveis já estavam em taxa percentual.
} 
Além da especificação básica presente na expressão (1), estimou-se outras especificações do modelo que decompõem o efeito da recessão sobre os grupos para cada ano após 2008, de tal forma que foi possível estimar a duração do impacto da crise de 2008 sobre o crescimento do emprego local.

Para evitar possíveis problemas com autocorrelação e heterocedasticidade nos resíduos $u_{i t}$ foram utilizados, como usual, erros padrão robustos propostos por Arellano (1987). Além disso, como apontam Bertrand et al (2004), Angrist e Pischke (2008) e Redding e Sturm (2008), as estimações dos erros padrão convencionais podem ser inconsistentes o que justifica a utilização de clusters nos resíduos. Assim sendo, os resíduos foram agrupados em clusters de município.

Os dados relacionados às variáveis associadas ao crescimento do emprego, à composição da mão de obra e à composição setorial dos municípios foram extraídas da Relação Anual de Informações Sociais (RAIS) do Ministério do Trabalho e Emprego. Essas variáveis referem-se aos vínculos ativos em 31 de dezembro de cada ano. As variáveis com aspectos geográficos como latitude e longitude nos municípios foram extraídas das bases do Instituto Brasileiro de Geografia e Estatística (IBGE). Também do IBGE foram obtidas as populações e áreas municipais utilizadas para a construção das densidades populacionais. Quanto à escolha do período, optou-se por abranger os anos de 2003-2011, possibilitando observar-se o crescimento do emprego para quatro anos antes da recessão ocorrida a partir da segunda metade de 2008, e quatro anos após a recessão.

\section{Estatísticas descritivas e composição das amostras}

A caracterização das amostras de municípios brasileiros ${ }^{9}$ usada na pesquisa está sumarizada na Tabela 1 abaixo. Observe-se que as três primeiras amostras foram utilizadas para as regressões cuja variável dependente é a taxa de crescimento do emprego municipal total; enquanto, as outras duas amostras foram utilizadas para as regressões cuja variável dependente é o crescimento do emprego na indústria de transformação. Para as três primeiras amostras o indicador definidor dos grupos é o nível populacional do município, assim, por exemplo, a Amostra 2 é composta pelos municípios correspondentes aos $25 \%$ mais populosos do Brasil e a Amostra 3 apenas pelos municípios brasileiros com mais de cem mil habitantes, ambas para

\footnotetext{
${ }^{9}$ Seguindo Brunello e Langella (2016), a definição dos grupos de alta e baixa aglomeração utilizada é de 2003, de tal forma que é possível trata-la como exógena a crise de 2008, com relativa segurança.
} 
o período de 2003. Já as três amostras seguintes utilizam municípios com nível de emprego na indústria de transformação no ano de 2003 igual ou superior a 500 e 1000 trabalhadores, respectivamente.

Essa participação dos municípios busca evitar a utilização de municípios com nível de emprego, total ou industrial, igual ou muito próximo a zero em algum período. O segundo objetivo é controlar para possíveis efeitos de escala, já que municípios com nível de emprego excessivamente baixos poderiam apresentar taxas de variação do emprego elevadas, distorcendo os efeitos das aglomerações. O último objetivo da estratégia de partição em grupos de municípios é analisar se os efeitos estimados persistem, mesmo com amostras mais homogêneas em termos de aglomeração.

Tabela 1 - Definição das amostras utilizadas.

\begin{tabular}{l|l}
\hline Amostra 1 & $\begin{array}{l}\text { Total de 5,559 Municípios com dados sobre o emprego disponíveis para o } \\
\text { período 2003-2011. }\end{array}$ \\
\hline Amostra 2 & $\begin{array}{l}\text { Total de 1,389 Municípios, representado pelos 25\% mais populosos em 2003, } \\
\text { presentes na Amostra 1 }\end{array}$ \\
\hline Amostra 3 & $\begin{array}{l}\text { Total de 239 Municípios, presentes na Amostra 1, com população superior a } \\
100,000 \text { habitantes em 2003. }\end{array}$ \\
\hline Amostra 4 & $\begin{array}{l}\text { Total de 1,123 Municípios, presentes na Amostra 1, com número de } \\
\text { trabalhadores na indústria de transformação superior a 500 em 2003. }\end{array}$ \\
\hline Amostra 5 & $\begin{array}{l}\text { Total de 784 Municípios, presentes na Amostra 1, com número de } \\
\text { trabalhadores na indústria de transformação superior a 1,000 em 2003. }\end{array}$ \\
\hline
\end{tabular}

Fonte: Elaborado pelos autores.

É possível observar que a distribuição espacial de municípios brasileiros é heterogênea entre os estados brasileiros (Tabela 2) com uma concentração expressiva de municípios no Sudeste-Sul, enquanto que o Norte apresenta menor número total de municípios. Essa heterogeneidade espacial na distribuição dos municípios é um indicativo da existência de aglomerações econômicas nas regiões Sul e Sudeste. Esse padrão é reforçado ao impor restrições nas amostras baseadas no tamanho da população e no nível de emprego industrial.

Após definir as amostras, foram construídos, a partir das densidades populacionais dos municípios, ou seja, pelo número de habitantes por quilômetro quadrado, os grupos de municípios considerados de alta e baixa aglomeração. A densidade pode depender de maneira crucial das unidades espaciais escolhidas, o que pode levar a problemas de estimação, como apontam Briant et al (2010). Portanto, ao escolher a unidade referência municípios buscou-se minimizar ao máximo o efeito da heterogeneidade nas densidades locais. 
A Figura 1 apresenta os histogramas da densidade populacional dos municípios brasileiros presentes nas cinco amostras, com as escalas utilizadas sendo de 100 pessoas por quilômetro quadrado. De maneira geral, as densidades populacionais no Brasil são baixas para a maioria dos municípios. Para a amostra 1, por exemplo, dos 5.559 municípios utilizados, mais de 4.000 apresentam densidade populacional menor que 100 habitantes por quilômetro quadrado. Na amostra 3, apenas com municípios com população superior a 100.000 habitantes o padrão se altera sensivelmente, com a distribuição menos concentrada nas menores densidades. Para as amostras em que foi utilizado o emprego industrial como fator de exclusão, as concentrações mostraram-se semelhantes à distribuição da população. A Figura 2 apresenta o mapa com os quartis da densidade populacional dos municípios brasileiros, com as cores mais escuras indicando cidades mais densas.

Figura 1 - Histograma da densidade populacional dos municípios brasileiros presentes nas cinco amostras.
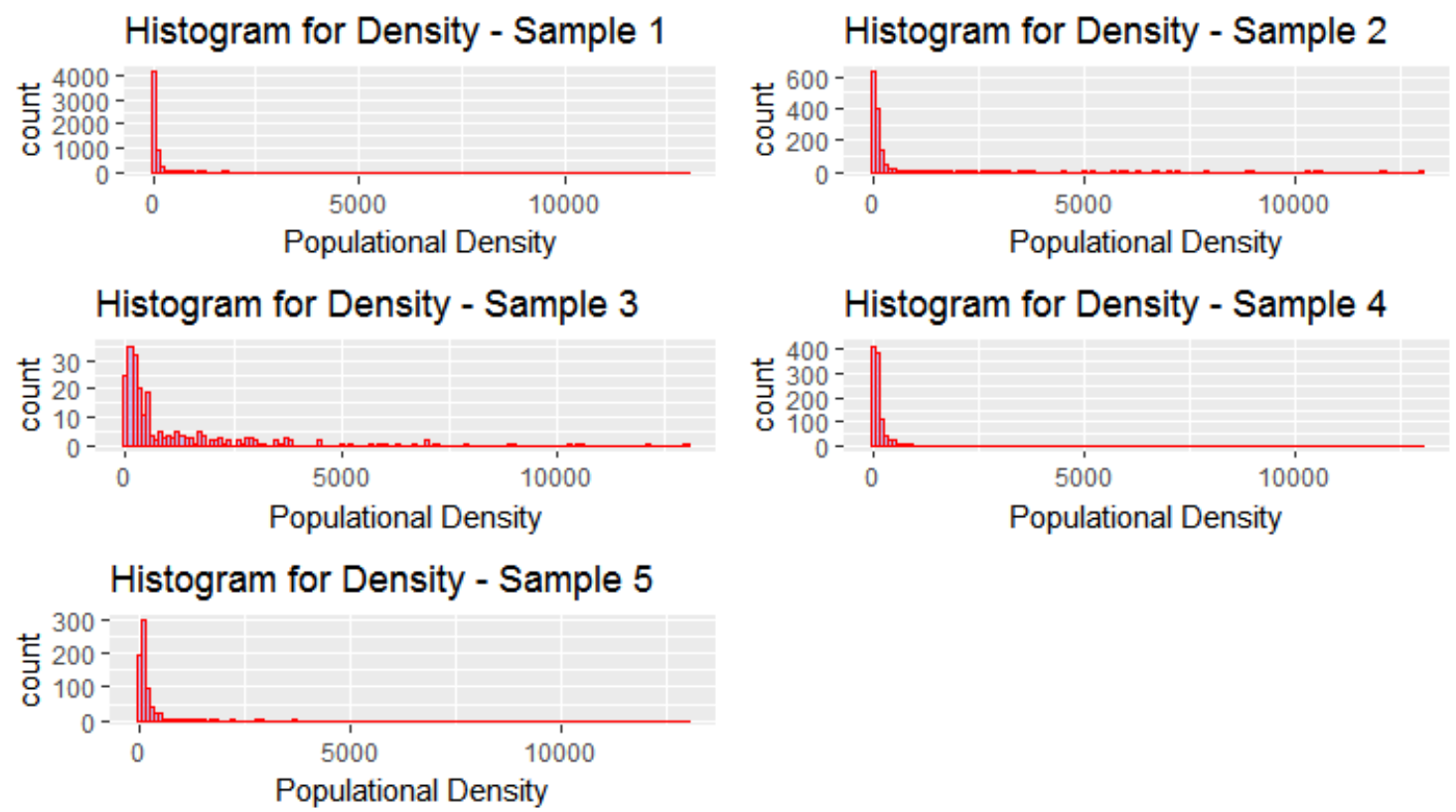

Fonte: Elaborado pelos autores.

Embora o processo de aglomeração seja dinâmico, o processo de formação dos centros urbanos em geral é lento, muitas vezes dependendo de fatores históricos (Fujita e Thisse, 2013). Como o período analisado aqui é relativamente curto, é de se esperar que os grupos distintos de municípios se mantenham relativamente estáveis em termos densidade populacional no período. Nesse sentido, a Tabela 3 apresenta os máximos, mínimos, os quartis e a mediana das densidades populacionais para cada amostra em 2003 e 2011. 
Para distinguir os municípios de alta e baixa aglomeração $(Q=1$ para os municípios do grupo de alta aglomeração e $Q=0$ para o grupo com baixa aglomeração no modelo a ser estimado), foram estimados a distribuição por quartis para cada amostra em 2003. Observe-se que para a Amostra 1, por exemplo, o grupo de baixa aglomeração foi constituído de municípios com densidade entre 0.14 a 11.24 , enquanto os municípios de alta aglomeração apresentaram densidade entre 49.21 e $12,976$.

Figura 2 - Quartis das densidades populacionais dos municípios brasileiros.

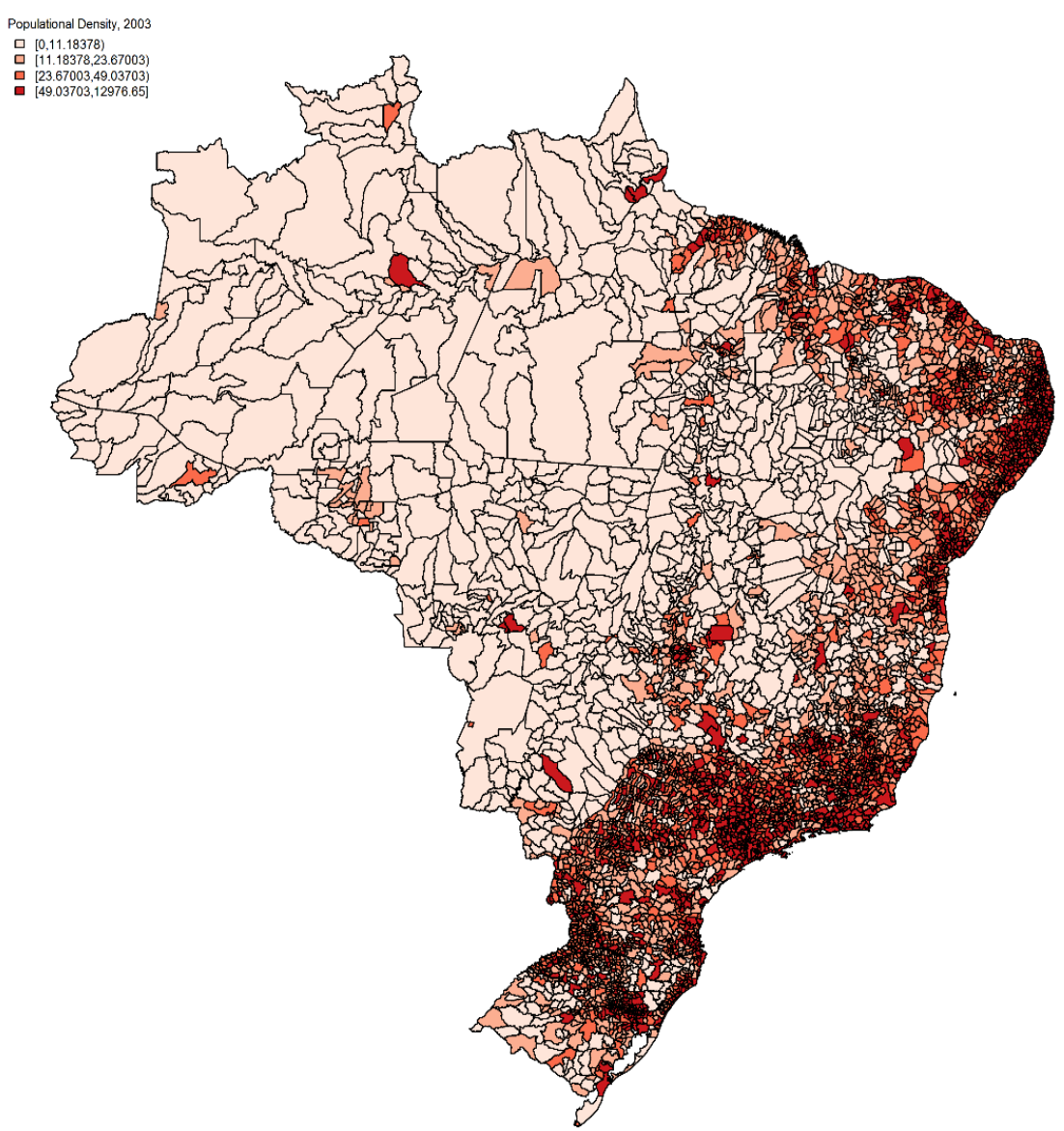

Fonte: Elaboração pelos autores. 
Tabela 2 - Participação dos estados em cada amostra

\begin{tabular}{|c|c|c|c|c|c|c|c|c|c|c|}
\hline & \multicolumn{2}{|c|}{ Amostra 1} & \multicolumn{2}{|c|}{ Amostra 2} & \multicolumn{2}{|c|}{ Amostra 3} & \multicolumn{2}{|c|}{ Amostra 4} & \multicolumn{2}{|c|}{ Amostra 5} \\
\hline & Municípios & $\begin{array}{c}\text { Percentual em } \\
\text { Relação ao } \\
\text { Total } \\
\end{array}$ & Municípios & $\begin{array}{c}\text { Percentual em } \\
\text { Relação ao } \\
\text { Total } \\
\end{array}$ & Municípios & $\begin{array}{c}\text { Percentual em } \\
\text { Relação ao } \\
\text { Total } \\
\end{array}$ & Municípios & $\begin{array}{c}\text { Percentual em } \\
\text { Relação ao } \\
\text { Total } \\
\end{array}$ & Municípios & $\begin{array}{c}\text { Percentual em } \\
\text { Relação ao } \\
\text { Total } \\
\end{array}$ \\
\hline $\mathrm{AC}$ & 22 & $0.40 \%$ & 5 & $0.36 \%$ & 1 & $0.42 \%$ & 1 & $0.09 \%$ & 1 & $0.13 \%$ \\
\hline $\mathrm{AL}$ & 102 & $1.83 \%$ & 33 & $2.38 \%$ & 2 & $0.84 \%$ & 21 & $1.87 \%$ & 20 & $2.55 \%$ \\
\hline $\mathrm{AM}$ & 62 & $1.12 \%$ & 27 & $1.94 \%$ & 1 & $0.42 \%$ & 2 & $0.18 \%$ & 2 & $0.26 \%$ \\
\hline $\mathrm{AP}$ & 16 & $0.29 \%$ & 3 & $0.22 \%$ & 1 & $0.42 \%$ & 1 & $0.09 \%$ & 1 & $0.13 \%$ \\
\hline BA & 417 & $7.50 \%$ & 139 & $10.01 \%$ & 14 & $5.86 \%$ & 40 & $3.56 \%$ & 28 & $3.57 \%$ \\
\hline $\mathrm{CE}$ & 184 & $3.31 \%$ & 82 & $5.90 \%$ & 6 & $2.51 \%$ & 25 & $2.23 \%$ & 21 & $2.68 \%$ \\
\hline DF & 1 & $0.02 \%$ & 1 & $0.07 \%$ & 1 & $0.42 \%$ & 1 & $0.09 \%$ & 1 & $0.13 \%$ \\
\hline ES & 78 & $1.40 \%$ & 28 & $2.02 \%$ & 7 & $2.93 \%$ & 19 & $1.69 \%$ & 10 & $1.28 \%$ \\
\hline GO & 245 & $4.41 \%$ & 42 & $3.02 \%$ & 7 & $2.93 \%$ & 33 & $2.94 \%$ & 19 & $2.42 \%$ \\
\hline MA & 217 & $3.90 \%$ & 68 & $4.90 \%$ & 6 & $2.51 \%$ & 9 & $0.80 \%$ & 5 & $0.64 \%$ \\
\hline MG & 853 & $15.34 \%$ & 150 & $10.80 \%$ & 26 & $10.88 \%$ & 147 & $13.09 \%$ & 98 & $12.50 \%$ \\
\hline MS & 77 & $1.39 \%$ & 18 & $1.30 \%$ & 2 & $0.84 \%$ & 16 & $1.42 \%$ & 8 & $1.02 \%$ \\
\hline MT & 139 & $2.50 \%$ & 22 & $1.58 \%$ & 3 & $1.26 \%$ & 30 & $2.67 \%$ & 14 & $1.79 \%$ \\
\hline PA & 143 & $2.57 \%$ & 83 & $5.98 \%$ & 7 & $2.93 \%$ & 30 & $2.67 \%$ & 21 & $2.68 \%$ \\
\hline $\mathrm{PB}$ & 223 & $4.01 \%$ & 24 & $1.73 \%$ & 3 & $1.26 \%$ & 11 & $0.98 \%$ & 9 & $1.15 \%$ \\
\hline PE & 185 & $3.33 \%$ & 83 & $5.98 \%$ & 10 & $4.18 \%$ & 37 & $3.29 \%$ & 26 & $3.32 \%$ \\
\hline PI & 222 & $3.99 \%$ & 21 & $1.51 \%$ & 2 & $0.84 \%$ & 5 & $0.45 \%$ & 3 & $0.38 \%$ \\
\hline PR & 399 & $7.18 \%$ & 77 & $5.54 \%$ & 14 & $5.86 \%$ & 114 & $10.15 \%$ & 77 & $9.82 \%$ \\
\hline RJ & 92 & $1.65 \%$ & 58 & $4.18 \%$ & 22 & $9.21 \%$ & 42 & $3.74 \%$ & 31 & $3.95 \%$ \\
\hline RN & 167 & $3.00 \%$ & 19 & $1.37 \%$ & 3 & $1.26 \%$ & 9 & $0.80 \%$ & 6 & $0.77 \%$ \\
\hline RO & 52 & $0.94 \%$ & 16 & $1.15 \%$ & 2 & $0.84 \%$ & 10 & $0.89 \%$ & 7 & $0.89 \%$ \\
\hline $\mathrm{RR}$ & 15 & $0.27 \%$ & 1 & $0.07 \%$ & 1 & $0.42 \%$ & 1 & $0.09 \%$ & 0 & $0.00 \%$ \\
\hline RS & 496 & $8.92 \%$ & 87 & $6.26 \%$ & 17 & $7.11 \%$ & 131 & $11.67 \%$ & 95 & $12.12 \%$ \\
\hline $\mathrm{SC}$ & 293 & $5.27 \%$ & 48 & $3.46 \%$ & 10 & $4.18 \%$ & 119 & $10.60 \%$ & 80 & $10.20 \%$ \\
\hline SE & 75 & $1.35 \%$ & 18 & $1.30 \%$ & 2 & $0.84 \%$ & 10 & $0.89 \%$ & 8 & $1.02 \%$ \\
\hline SP & 645 & $11.60 \%$ & 227 & $16.34 \%$ & 67 & $28.03 \%$ & 255 & $22.71 \%$ & 191 & $24.36 \%$ \\
\hline TO & 139 & $2.50 \%$ & 9 & $0.65 \%$ & 2 & $0.84 \%$ & 4 & $0.36 \%$ & 2 & $0.26 \%$ \\
\hline Total & 5559 & $100.00 \%$ & 1389 & $100.00 \%$ & 239 & $100.00 \%$ & 1123 & $100.00 \%$ & 784 & $100.00 \%$ \\
\hline
\end{tabular}

Fonte: Elaborado pelos autores. 
A amostra mais discrepante em relação às outras é a formada pelos municípios com população superior a 100,000 habitantes em 2003, na qual o grupo de baixa aglomeração contempla cidades com densidade entre 10.38 e 159.25 e o grupo de alta aglomeração apresenta cidades com densidades entre 1,620 e 12,976.

Entende-se que a variação nas densidades populacionais poderia gerar viés de seleção na estimação difference-in-differences, com municípios migrando de grupo ao longo dos períodos (Angrist e Pischke, 2008). No entanto, é possível observar pela Tabela 3, que a maioria dos municípios permaneceu no mesmo quartil de densidade ao longo de todo o período. Assim, entre 2003 e 2011, em todas as cinco amostras utilizadas nas estimações mais de $90 \%$ dos municípios permaneceram no mesmo quartil.

Tabela 3 - Municípios presentes no mesmo quartil de distribuição da densidade populacional em 2003 e 2011.

\begin{tabular}{c|c|c|c}
\hline & $\begin{array}{c}\text { Total de } \\
\text { Municípios }\end{array}$ & $\begin{array}{c}\text { Municípios no Mesmo } \\
\text { Quartil em 2003 e } \\
2011\end{array}$ & $\begin{array}{c}\text { Percentual de Municípios no Mesmo } \\
\text { Quartil }\end{array}$ \\
\hline Amostra 1 & 5,559 & 5,150 & $92.64 \%$ \\
\hline Amostra 2 & 1,389 & 1,317 & $94.82 \%$ \\
\hline Amostra 3 & 239 & 231 & $96.65 \%$ \\
\hline Amostra 4 & 1,123 & 1,061 & $94.48 \%$ \\
\hline Amostra 5 & 784 & 742 & $94.64 \%$ \\
\hline
\end{tabular}

Fonte: Elaborado pelos autores.

Tabela 4 - Crescimento médio, máximo e mínimo do emprego total nos municípios brasileiros entre 2003-2011.

\begin{tabular}{c|c|l|c|l|c}
\hline \multirow{2}{*}{ Amostra } & \multirow{2}{*}{ Média } & \multicolumn{2}{|c|}{ Mínimo } & \multicolumn{2}{c}{ Máximo } \\
\cline { 3 - 6 } & & \multicolumn{1}{|c|}{ Município } & Taxa & \multicolumn{1}{c}{ Município } & Taxa \\
\hline 1 & $6.7 \%$ & Carnaubeira da Penha-PE & $-53.96 \%$ & São João do Caru-MA & $79.96 \%$ \\
2 & $6.5 \%$ & Fonte Boa-AM & $-34.47 \%$ & Melgaço-PA & $47.40 \%$ \\
3 & $6.3 \%$ & Poá-SP & $-4.76 \%$ & Boa Vista-RR & $14.24 \%$ \\
5 & $4.7 \%$ & Primavera-PE & $-73.55 \%$ & Timbauba-PE & $29.80 \%$ \\
6 & $4.2 \%$ & Primavera-PE & $-73.55 \%$ & Vitória de Santo Antão-PE & $22.54 \%$ \\
\hline
\end{tabular}

Fonte: Elaborado pelos autores.

A Tabela 4 apresenta a média, o máximo e o mínimo do crescimento observado do emprego entre 2003-2011 nos municípios brasileiros presentes nas cinco amostras. A média dos crescimentos para a Amostra 1, foi de $6.7 \%$ no período, com a menor taxa de crescimento observada $(-53,96 \%)$ em Carnaubeira da Penha em Pernambuco e o maior crescimento observado foi em São João do Caru no Maranhão, de 79,96\%. A Figura 3 
apresenta o crescimento médio do emprego, dividido em quintis, para os municípios brasileiros, onde as cores mais escuras são os municípios com maior crescimento.

Figura 3 - Crescimento médio do emprego nos munícipios brasileiros entre 2004-2011.

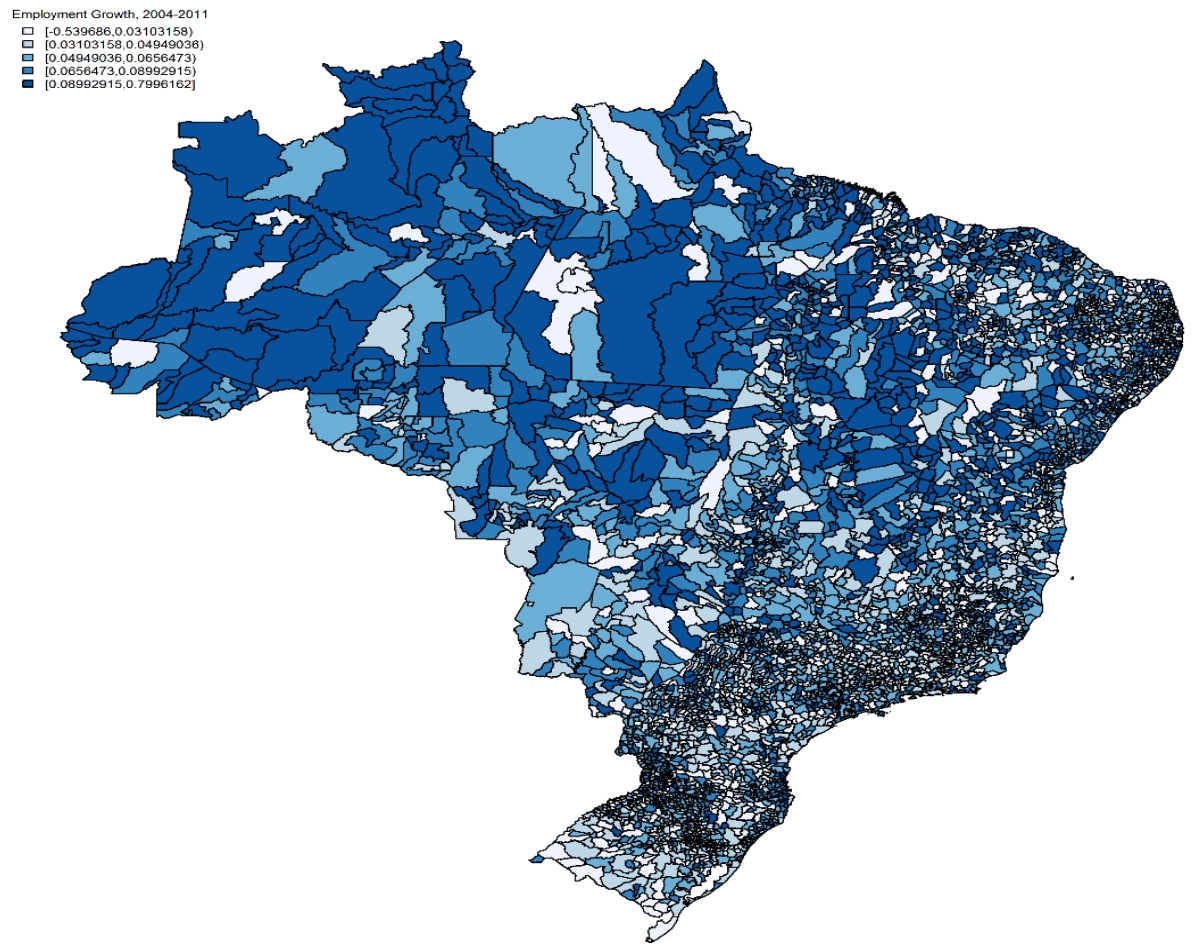

Fonte: Elaborado pelos autores.

Para as três primeiras amostras considerou-se o crescimento do emprego total. Já para as duas últimas amostras foi considerado o crescimento do emprego na indústria de transformação. É possível observar um crescimento menor no emprego ao considerar apenas a indústria de transformação.

A Figura 4 apresenta o crescimento do emprego para os grupos de alta e baixa aglomeração. Nesse caso, é possível observar que para as duas primeiras amostras que utilizam o emprego total, os municípios de baixa aglomeração apresentaram maior média de crescimento exceto entre os anos de 2007-2008. Para a terceira amostra os municípios de alta aglomeração apresentaram menor crescimento entre 2007 e 2008, e maior crescimento entre 2005-2006, 2006-2007 e 2009-2010.

Para o crescimento do emprego na indústria de transformação, as duas amostras restantes mostraram um crescimento superior para os municípios de alta aglomeração, 
exceto nos períodos iniciais e finais da série analisada. Para o ano em que ocorreu a recessão, é possível observar uma queda mais acentuada do crescimento nos municípios com baixa aglomeração.

Figura 4 - Taxa de Crescimento do Emprego Para os Grupos de Municípios de Alta e Baixa Aglomeração.
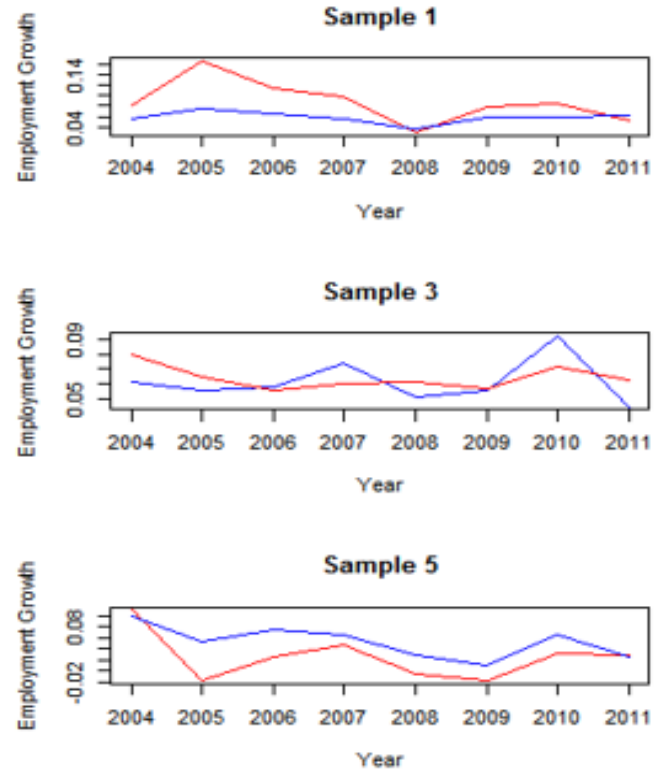

Sample 1

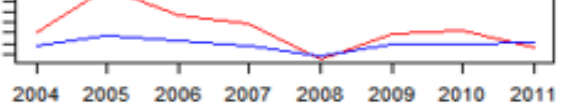

Year

Sample 3

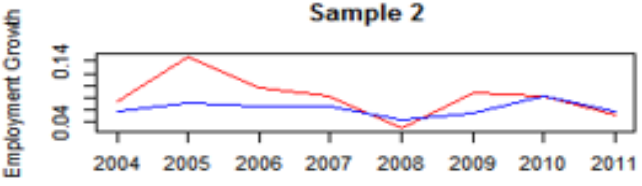

Year

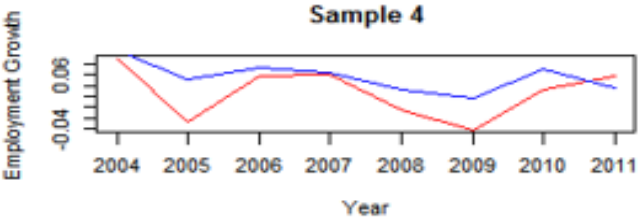

Year

Low Agglomeration High Agglomeration

Fonte: Elaborado pelos autores.

\section{Discussão dos resultados}

A Tabela 6 apresenta os resultados da estimação utilizando o crescimento do emprego total como variável dependente. Para a Amostra 1 os municípios de alta aglomeração apresentaram crescimento menor ao longo do período total, evidenciado pelo parâmetro $\beta_{q}=-0.024$, enquanto que para o período pós-recessão o crescimento do emprego mostrou-se menor que o anterior a recessão, $\operatorname{com} \beta_{j}=-0.047$. O parâmetro de interesse, que mede a diferença no impacto da recessão sobre os grupos de alta e baixa aglomeração, indicou um impacto menor da crise de 2008 sobre os municípios de alta aglomeração, $\operatorname{com} \beta_{d}=0.042$.

Quanto às variáveis de controle, a participação feminina no mercado de trabalho e a especialização industrial municipal, medida pelo índice de Hirschman-Herfindahl, apresentaram impacto positivo e significativo sobre a geração de emprego local; enquanto, que a participação do setor agrícola apresentou impacto negativo. Com relação à latitude, como a mesma possui sinal negativo, o parâmetro positivo indicou menor crescimento para os municípios mais distantes do litoral. Já a longitude, o sinal negativo 
indica maior crescimento para os municípios do Sul do país. Os demais controles não apresentaram significância estatística. Na segunda especificação, decompondo os efeitos da recessão por ano, observa-se que os municípios de alta aglomeração apresentaram crescimento superior e crescente entre 2008-2011.

Para a segunda amostra, restrita aos municípios que estão entre os $25 \%$ mais populosos do país, não se observou diferença de crescimento entre os grupos ao longo de todos os períodos, com $\beta_{q}$ não significativo. Para o período pós crise, porém, as taxas de crescimento foram inferiores ao período anterior à crise e o impacto total indica que os municípios de maior aglomeração apresentaram crescimento superior em 0.014. Ao decompor o resultado em todos os anos após a recessão, constata-se que para os anos de 2008 e 2009 não houve diferença nas taxas de crescimento do emprego nessa amostra, com parâmetros não significativos; enquanto, que a partir de 2010 houve maior crescimento para os municípios de alta aglomeração.

O resultado indica que a recessão teve efeito imediato similar entre os grupos dessa amostra, mas o grupo de alta aglomeração apresentou recuperação mais intensa nos períodos seguintes. Quanto às variáveis de controle, apresentaram significância estatística apenas a participação feminina, a taxa de trabalhadores de baixa qualificação, o índice de especialização e a latitude municipal.

Para a Amostra 3, dos municípios com mais de cem mil habitantes, não se observou diferenças no crescimento entre os períodos anteriores e após recessão (com $\beta_{j}$ não significativo). Ainda, para os quatro períodos conjuntos que se seguiram a recessão, não houve diferença no crescimento entre os dois grupos ( $\beta_{d}$ não significativo). Novamente, contudo, os municípios de alta aglomeração apresentaram crescimento maior do que os de baixa aglomeração para o período inteiro, com $\beta_{q}=0.011$. Em 2008 não houve diferença no crescimento dos grupos, porém, o grupo de alta aglomeração cresceu menos em 2009. Para 2010, ocorreu uma recuperação mais robusta dos municípios com alta aglomeração, que, no entanto, voltam a crescer menos em 2011. Para essa amostra, os controles que apresentaram significância estatística foram os salários e a parcela de trabalhadores com alta qualificação, o que indica uma maior dependência dos municípios maiores de mão de obra qualificada. Também foram significativos o índice de especialização industrial e a posição geográfica favorável em relação ao litoral. 
Tabela 5 - Resultados para a estimação com difference-in-differences e crescimento do emprego total como variável dependente.

\begin{tabular}{|c|c|c|c|c|c|c|}
\hline \multirow{3}{*}{ Variáveis } & \multicolumn{6}{|c|}{ Variável Dependente: Crescimento do Emprego Total } \\
\hline & \multicolumn{2}{|c|}{ Amostra 1} & \multicolumn{2}{|c|}{ Amostra 2} & \multicolumn{2}{|c|}{ Amostra 3} \\
\hline & (1) & $(2)$ & (3) & (4) & (5) & (6) \\
\hline \multirow{2}{*}{ Intercepto } & $0.041 *$ & $0.041^{*}$ & 0.144 & 0.144 & 0.024 & 0.023 \\
\hline & $(0.022)$ & $(0.022)$ & $(0.035)$ & $(0.035)$ & $(0.019)$ & (0.019) \\
\hline \multirow{2}{*}{ Alta Aglomeração (Q) } & $-0.024 * * *$ & $-0.024 * * *$ & -0.007 & -0.007 & $0.011 * *$ & $0.011 * *$ \\
\hline & $(0.005)$ & $(0.005)$ & $(0.006)$ & $(0.006)$ & $(0.005)$ & $(0.005)$ \\
\hline \multirow{2}{*}{ Período pós-crise (J) } & $-0.047 * * *$ & $-0.047 * * *$ & $-0.019 * * *$ & $-0.019 * * *$ & -0.002 & -0.003 \\
\hline & $(0.006)$ & $(0.006)$ & $(0.007)$ & $(0.007)$ & $(0.004)$ & $(0.004)$ \\
\hline \multirow{2}{*}{ Alta Aglomeração X Período pós-crise } & $0.042 * * *$ & & $0.014^{*}$ & & -0.002 & \\
\hline & $(0.006)$ & & $(0.007)$ & & $(0.006)$ & \\
\hline \multirow{2}{*}{ Alta Aglomeração X 2008} & & $0.028 * * *$ & & 0.009 & & -0.007 \\
\hline & & $(0.007)$ & & $(0.008)$ & & $(0.008)$ \\
\hline \multirow{2}{*}{ Alta Aglomeração X 2009} & & $0.035^{* * *}$ & & -0.006 & & $-0.019 * *$ \\
\hline & & $(0.007)$ & & $(0.008)$ & & $(0.009)$ \\
\hline \multirow{2}{*}{ Alta Aglomeração X 2010} & & $0.051 * * *$ & & $0.038^{* * *}$ & & $0.030 * * *$ \\
\hline & & $(0.007)$ & & $(0.008)$ & & $(0.008)$ \\
\hline \multirow{2}{*}{ Alta Aglomeração X 2011} & & $0.053 * * *$ & & $0.017^{*}$ & & $-0.015^{* *}$ \\
\hline & & $(0.007)$ & & $(0.009)$ & & $(0.007)$ \\
\hline \multirow{2}{*}{ Salários (gW) } & 0.018 & 0.019 & -0.201 & -0.202 & $0.239 * * *$ & $0.246 * * *$ \\
\hline & $(0.088)$ & $(0.088)$ & $(0.169)$ & $(0.169)$ & $(0.068)$ & $(0.068)$ \\
\hline \multirow{2}{*}{ Alta Qualificação (gHS) } & -0.117 & -0.117 & 0.073 & 0.074 & $0.178 * *$ & $0.195 * *$ \\
\hline & $(0.161)$ & $(0.161)$ & $(0.185)$ & $(0.185)$ & $(0.085)$ & $(0.086)$ \\
\hline \multirow{2}{*}{ Baixa Qualificação (gLS) } & 0.141 & 0.139 & $0.473^{*}$ & $0.472 *$ & 0.188 & 0.182 \\
\hline & $(0.146)$ & $(0.147)$ & $(0.252)$ & $(0.252)$ & $(0.148)$ & $(0.148)$ \\
\hline \multirow{2}{*}{ Participação Feminina (gWomen) } & $1.165^{* * *}$ & $1.165^{* * *}$ & $1.538 * * *$ & $1.535 * * *$ & -0.156 & -0.176 \\
\hline & $(0.272)$ & $(0.272)$ & $(0.378)$ & $(0.378)$ & $(0.201)$ & $(0.200)$ \\
\hline \multirow{2}{*}{ Participação do Setor Agrícola (gA) } & $-0.696 * * *$ & $-0.696 * * *$ & -0.296 & -0.298 & -0.379 & -0.375 \\
\hline & $(0.164)$ & $(0.164)$ & $(0.242)$ & $(0.242)$ & $(0.255)$ & $(0.257)$ \\
\hline \multirow{2}{*}{ Participação do Setor Industrial (gl) } & 0.043 & 0.043 & -0.043 & -0.046 & -0.014 & -0.025 \\
\hline & (0.159) & $(0.159)$ & $(0.224)$ & $(0.224)$ & $(0.211)$ & $(0.209)$ \\
\hline \multirow{2}{*}{ Índice de Hirschman-Herfindahl (gHHI) } & $0.559 * * *$ & $0.560 * * *$ & $0.711^{* * *}$ & $0.712^{* * *}$ & $0.336 * * *$ & $0.339 * * *$ \\
\hline & $(0.055)$ & $(0.055)$ & $(0.081)$ & $(0.081)$ & $(0.032)$ & $(0.031)$ \\
\hline \multirow{2}{*}{ Latitude (Lat) } & $0.003 * * *$ & $0.003 * * *$ & $0.002 * * *$ & $0.002 * * *$ & $0.001 * * *$ & $0.001 * * *$ \\
\hline & $(0.000)$ & $(0.000)$ & $(0.000)$ & $(0.000)$ & $(0.000)$ & $(0.000)$ \\
\hline \multirow{2}{*}{ Longitude (Lon) } & $-0.002 * * *$ & $-0.002 * * *$ & -0.001 & -0.001 & $-0.001 * *$ & $-0.001 * *$ \\
\hline & $(0.000)$ & $(0.000)$ & $(0.000)$ & $(0.000)$ & $(0.000)$ & $(0.000)$ \\
\hline $\mathrm{R}^{2}$ & 0.227 & 0.227 & 0.430 & 0.432 & 0.293 & 0.317 \\
\hline F-statistic & 543.43 & 435.27 & 350.02 & 281.13 & 32.43 & 28.98 \\
\hline Total de Municípios & 2768 & 2768 & 695 & 695 & 119 & 119 \\
\hline Municípios de Alta Aglomeração & 1388 & 1388 & 347 & 347 & 59 & 59 \\
\hline Municípios de Baixa Aglomeração & 1380 & 1380 & 348 & 348 & 60 & 60 \\
\hline Períodos & 8 & 8 & 8 & 8 & 8 & 8 \\
\hline $\mathrm{N}$ & 22144 & 22144 & 5560 & 5560 & 952 & 952 \\
\hline
\end{tabular}

* significante a um nível de10\%, ${ }^{* *}$ significante a um nível de 5\%, $* * *$ significante a um nível de $1 \%$ Fonte: Elaborado pelos autores

Na Tabela 6 tem-se o crescimento do emprego na indústria de transformação. Ênfase para a Amostra 4 com municípios que possuíam pelo menos 500 trabalhadores em 
2003, o grupo de alta aglomeração apresentou maior crescimento do período, embora na pós-recessão a diferença entre crescimento dos grupos não tenha seja significância. Observou-se nos municípios de alta aglomeração um crescimento inferior de 2009 e 2011.

Tabela 6 - Resultados para a estimação com difference-in-differences e crescimento do emprego na indústria de transformação como variável dependente.

\begin{tabular}{|c|c|c|c|c|}
\hline \multirow{3}{*}{ Variáveis } & \multicolumn{4}{|c|}{$\begin{array}{l}\text { Variável Dependente: Crescimento do Emprego na } \\
\text { Indústria de Transformação }\end{array}$} \\
\hline & \multicolumn{2}{|c|}{ Amostra 4} & \multicolumn{2}{|c|}{ Amostra 5} \\
\hline & (3) & (4) & (5) & (6) \\
\hline \multirow{2}{*}{ Intercepto } & $0.079 * * *$ & $0.080 * * *$ & $0.074 * * *$ & $0.075^{* * *}$ \\
\hline & $(0.027)$ & $(0.027)$ & $(0.025)$ & $(0.025)$ \\
\hline \multirow{2}{*}{ Alta Aglomeração (Q) } & $0.029 * * *$ & $0.029 * * *$ & $0.030 * * *$ & $0.030 * * *$ \\
\hline & $(0.007)$ & $(0.007)$ & $(0.006)$ & $(0.006)$ \\
\hline \multirow{2}{*}{ Período pós-crise (J) } & $-0.031 * * *$ & $-0.031 * * *$ & $-0.025^{* * *}$ & $-0.025 * * *$ \\
\hline & $(0.007)$ & $(0.007)$ & $(0.008)$ & $(0.008)$ \\
\hline \multirow{2}{*}{ Alta Aglomeração X Período pós-crise } & -0.013 & & $-0.020 * *$ & \\
\hline & $(0.009)$ & & $(0.009)$ & \\
\hline \multirow{2}{*}{ Alta Aglomeração X 2008} & & -0.016 & & $-0.020 *$ \\
\hline & & $(0.011)$ & & $(0.010)$ \\
\hline \multirow{2}{*}{ Alta Aglomeração X 2009} & & $-0.030 * * *$ & & $-0.041 * * *$ \\
\hline & & $(0.010)$ & & $(0.010)$ \\
\hline \multirow{2}{*}{ Alta Aglomeração X 2010} & & 0.016 & & 0.009 \\
\hline & & $(0.010)$ & & $(0.010)$ \\
\hline \multirow{2}{*}{ Alta Aglomeração X 2011} & & $-0.022 * *$ & & $-0.029 * * *$ \\
\hline & & $(0.011)$ & & $(0.010)$ \\
\hline \multirow{2}{*}{ Salários (gW) } & $0.455^{* * *}$ & $0.451 * * *$ & $0.311^{* * *}$ & $0.307 * * *$ \\
\hline & $(0.163)$ & $(0.163)$ & $(0.065)$ & $(0.065)$ \\
\hline \multirow{2}{*}{ Alta Qualificação (gHS) } & -0.912 & -0.906 & -0.152 & -0.149 \\
\hline & $(0.737)$ & $(0.736)$ & $(0.488)$ & $(0.487)$ \\
\hline \multirow{2}{*}{ Baixa Qualificação (gLS) } & $0.937 * * *$ & $0.937 * * *$ & $1.181 * * *$ & $1.180^{* * *}$ \\
\hline & $(0.231)$ & $(0.232)$ & $(0.331)$ & $(0.331)$ \\
\hline \multirow{2}{*}{ Participação Feminina (gWomen) } & -0.036 & -0.034 & -0.832 & -0.824 \\
\hline & $(0.396)$ & $(0.396)$ & $(0.622)$ & $(0.623)$ \\
\hline \multirow{2}{*}{ Índice de Hirschman-Herfindahl (gHHI) } & $0.535^{* * *}$ & $0.536 * * *$ & $0.381 * * *$ & $0.382 * * *$ \\
\hline & $(0.085)$ & $(0.085)$ & $(0.086)$ & $(0.086)$ \\
\hline \multirow{2}{*}{ Latitude (Lat) } & -0.001 & -0.001 & -0.001 & -0.001 \\
\hline & $(0.000)$ & $(0.000)$ & $(0.000)$ & $(0.000)$ \\
\hline \multirow{2}{*}{ Longitude (Lon) } & $0.001^{*}$ & $0.001^{*}$ & 0.001 & 0.001 \\
\hline & $(0.000)$ & $(0.000)$ & $(0.000)$ & $(0.000)$ \\
\hline $\mathrm{R}^{2}$ & 0.219 & 0.220 & 0.250 & 0.253 \\
\hline F-statistic & 125.44 & 97.33 & 104.18 & 81.41 \\
\hline Total de Municípios & 560 & 560 & 392 & 392 \\
\hline Municípios de Alta Aglomeração & 280 & 280 & 196 & 196 \\
\hline Municípios de Baixa Aglomeração & 280 & 280 & 196 & 196 \\
\hline Períodos & 8 & 8 & 8 & 8 \\
\hline $\mathrm{N}$ & 4480 & 4480 & 3136 & 3136 \\
\hline
\end{tabular}

* significante a um nível de10\%, ** significante a um nível de 5\%, *** significante a um nível de $1 \%$ Fonte: Elaborado pelos autores 
A mesma análise para a Amostra 5 indica uma diferença negativa no efeito da crise de 2008 entre os grupos de alta e baixa aglomeração, assim, ao considerar todos os quatro anos após a recessão, o grupo de alta aglomeração sofreu um impacto maior da recessão. Ao considerar a decomposição dos períodos pós-crise, os municípios de alta aglomeração cresceram menos ao longo de todo o período e de forma negativa e significativa em 2008, 2009 e 2011. Para as Amostras 4 e 5, os controles que apresentaram significância estatística foram os salários, a parcela de trabalhadores de baixa qualificação e a especialização industrial.

Algumas observações complementares podem ser feitas em relação às estimações realizadas. Ao considerar o emprego total nos municípios, aqueles com alta aglomeração, de maneira geral, apresentaram crescimento superior aos de baixa aglomeração no período pós-recessão. Esse resultado, todavia, contrasta com o obtido ao considerar apenas o crescimento do emprego na indústria de transformação. $\mathrm{O}$ segundo ponto que deve ser destacado é que para o emprego total, as amostras mais homogêneas apresentaram diferenças mais modestas nas taxas de crescimento entre grupos no período pós-recessão.

Quando as amostras utilizadas são mais heterogêneas as diferenças foram mais acentuadas e isso pode fortalecer o papel das aglomerações no processo de crescimento do emprego. Por fim, os controles que apresentaram significância estatística variaram de maneira expressiva entre diferentes amostras, o que indica que algumas variáveis podem ser relevantes apenas para estruturas econômicas específicas. Uma exceção foi $\mathrm{p}$ resultado apresentado pela variável especialização industrial que teve impacto positivo e significativo em todas as amostras, o que reforça o papel positivo das externalidades MAR sobre o crescimento local no período.

\section{Considerações finais}

A recessão ocorrida em 2008 gerou efeitos diversos sobre a economia global nas economias de países emergentes como o Brasil. O propósito dessa pesquisa é analisar o impacto daquela crise sobre economias locais no Brasil. O resultado, de maneira geral, apontou um impacto mais severo da crise para os municípios de menor aglomeração. Os municípios com menores aglomerações apresentaram taxas de crescimento menores, mesmo quando o período pós crise foi decomposto ano a ano. A única exceção observada foi o comportamento da amostra, que incluía apenas municípios com mais de cem mil 
habitantes. Nesse caso, não se detectou diferenças significativas entre os municípios de baixa e alta aglomeração. Contudo, o comportamento do emprego na indústria de transformação mostrou alta sensibilidade negativa à crise de 2008 nos municípios de maior aglomeração. Ou seja, as taxas observadas de crescimento nesses municípios foram inferiores às taxas de crescimento dos municípios de baixa aglomeração.

Outro aspecto que merece destaque é o papel positivo e significativo da incidência local de trabalhadores de alta qualificação, no comportamento do emprego local em municípios com mais de cem mil habitantes. Entre as variáveis de controle utilizadas, a especialização industrial ou setorial do município é um fator importante para o emprego local e para diminuir o impacto da crise sobre o emprego local. Portanto, o crescimento da especialização implicou no crescimento do emprego local, resultado condizente com o considerado pelas externalidades MAR. Contudo, essa conclusão depende do setor industrial presente em cada região, e de como cada setor especifico reage às crises econômicas. Esses aspectos demandam pesquisas adicionais.

Normalmente, duas forças distintas atuam em direções contrárias numa aglomeração de atividades econômicas. Os links verticais entre as indústrias, por exemplo, podem, numa situação de crise econômica, piorar a dinâmica da economia local. Tal fato decorre de outras indústrias, que fazem parte da rede de fornecimento desse segmento, inicialmente afetada pela crise podem sofrer com a consequente queda da demanda, e isso pode desencadear uma crise sistêmica regional. Por outro lado, as externalidades como sharing, matching e learning, e mesmo externalidades do tipo MAR podem amenizar o impacto inicial da crise econômica e proteger os empregos das economias locais. Assim, o próximo passo da pesquisa é analisar quais forças atuaram para proteger o grupo de municípios com maior aglomeração no Brasil durante a crise de 2008. Esse tipo de pesquisa é importante para melhorar o desenho de políticas regionais efetivas para combater desigualdades regionais e para, por exemplo, minimizar o impacto de crises econômicas sobre as economias regionais menos desenvolvidas.

\section{Referências}

ANGRIST, J. D.; PISCHKE, J. S. Mostly harmless econometrics: an empiricist's companion. Princeton university press. 2008.

ARELLANO, M. Computing robust standard errors for within-groups estimators. Oxford Bulletin of Economics and Statistics, 49(4), 431-34. 1987. 
BADIA, D.; FIGUEREDO, L. Impacto das externalidades dinâmicas de escala sobre o crescimento do emprego industrial nas cidades brasileiras. Revista Econômica do Nordeste, Fortaleza, 10(2), 123-167. 2007.

BAUM-SNOW, N.; LUTZ, B. F. School desegregation, school choice, and changes in residential location patterns by race. American Economic Review, 101(7), 3019-46. 2011.

BAUM-SNOW, N.; PAVAN, R. Understanding the city size wage gap. The Review of economic studies, 79(1). 2012.

BERTRAND, M., DUFLO, E.; MULLAINATHAN, S. How much should we trust differences-in-differences estimates? The Quarterly Journal of Economics, 119(1), 249-275. 2004.

BLIEN, U.; SUEDEKUM, J. Local economic structure and industry development in Germany, 1993- 2001. Economics Bulletin, 15(17), 1-8. 2005.

BLIEN, U., SUEDEKUM, J.; WOLF, K. Local employment growth in West Germany: A dynamic panel approach. Labour Economics, 13(4), 445-458. 2006.

BRIANT, A., COMBES, P. P.; LAFOURCADE, M. Dots to boxes: do the size and shape of spatial units jeopardize economic geography estimations? Journal of Urban Economics, 67(3), 287-302. 2010.

BRUNELLO, G.; LANGELLA, M. Local agglomeration, entrepreneurship and the 2008 recession: Evidence from Italian industrial districts. Regional Science and Urban Economics, 58, 104-114. 2016.

CICCONE, A.; HALL, R. E. Productivity and the Density of Economic Activity. The American Economic Review, 86(1), 54-70. 1996.

COMBES, P. P. Economic structure and local growth: France, 1984-1993. Journal of urban economics, 47(3), 329-355. 2000.

COMBES, P. P.; DURANTON, G.; GOBILlON, L. Spatial wage disparities: Sorting matters! Journal of Urban Economics, 63(2), 723-742. 2008.

COMBES, P. P.; GOBILLON L. The empirics of agglomeration economies. In: Handbook of regional and urban economics. Vol. 5, pp. 247-348. Elsevier. 2015.

DE LA ROCA, J.; PUGA, D. Learning by working in big cities. The Review of Economic Studies, 84(1), 106-142. 2017.

DURANTON, G.; PUGA, D. Micro-foundations of urban agglomeration economies. In: HENDERSON, J. V.; THISSE, J. F. (ed) Handbook of regional and urban economics. Vol. 4, pp. 2063-2117. Elsevier. 2004.

FUJITA, M. A monopolistic competition model of spatial agglomeration: Differentiated product approach. Regional science and urban economics, 18(1), 87-124. 1988. 
FUJITA, M.; THISSE, J. F. Economics of agglomeration: cities, industrial location, and globalization. Cambridge University Press. 2013.

GLAESER, E. L.; KALLAL, H. D., SCHEINKMAN, J. A.; SHLEIFER, A. Growth in cities. Journal of Political Economy, 100(6), 1126-1152. 1992.

GLAESER, E. L.; MARE, D. C. Cities and skills. Journal of Labor Economics, 19(2), 316-342. 2001.

GREENSTONE, M., HORBECKH, R.; MORETTI, E. Identifying agglomeration spillovers: evidence from winners and losers of large plant openings. Journal of Political Economy, 118(3), 536-598. 2010.

GUISO, L.; SCHIVARDI, F. Spillovers in industrial districts. The Economic Journal, 117(516), 68-93. 2007.

HENDERSON, V.; KUNCORO, A.; TURNER, M. Industrial development in cities. Journal of Political Economy, 103(5), 1067-1090. 1995.

HANSON, G. H. Market potential, increasing returns and geographic concentration. Journal of International Economics, 67(1), 1-24. 2005.

JACOBS, J. The life of cities. Random House. 1969.

KRUGMAN, P. Increasing returns and economic geography. Journal of Political Economy, 99(3), 483-499. 1991.

MAMELI, F., FAGGIAN, A.; MCCANN, P. Employment growth in Italian local labour systems: issues of model specification and sectoral aggregation. Spatial Economic Analysis, 3(3), 343-360. 2008.

MANELLI, F.; FAGGIN, A.; MCCANN, P. Estimation of local employment growth: do sectoral aggregation and industry definition matter? Regional Studies, 48(11), 18131828. 2014.

MARSHALL, A. Principles of political economy. Maxmillan, New York. 1890.

MATLABA, V. J.; HOLMES, M., MCCANN, P.; POOT, J. Agglomeration externalities and 1981-2006 regional growth in Brazil. Studies in Regional Science, 42(1), 145-161. 2012.

MICUCCI, G.; DI GIACINTO, V. The producer service sector in Italy: long-term growth and its local determinants. Spatial Economic Analysis, 4(4), 391-425. 2009.

OTTAVIANO, G.; THISSE, J. F. Agglomeration and economic geography. In: Handbook of regional and urban economics. Vol. 4, pp. 2563-2608. Elsevier. 2004.

PORTER, Michael E. The competitive advantage of nations. New York: Free Press. 1990. 
REDDING, S. J.; STURM, D. M. The costs of remoteness: evidence from German division and reunification. American Economic Review, 98(5), 1766-97. 2008.

REDDING, S.; VENABLES, A. J. Economic geography and international inequality. Journal of international Economics, 62(1), 53-82. 2004.

SHIMER, R. Labor markets and business cycles. Princeton University Press. 2010.

VENABLES, A. J. Equilibrium locations of vertically linked industries. International Economic Review, 341-359. 1996.

VILADECANS-MARSAL, E Agglomeration economies and industrial location: citylevel evidence. Journal of Economic Geography, 4(5), 565-582. 2004. 